\title{
A Population-Based Study of Juvenile Disc Degeneration and Its Association with Overweight and Obesity, Low Back Pain, and Diminished Functional Status
}

\author{
By Dino Samartzis, DSc, Jaro Karppinen, MD, PhD, Florence Mok, MSc, Daniel Y.T. Fong, PhD, \\ Keith D.K. Luk, MCh(Orth), FRCSE, FRCSG, FRACS, FHKAM(Orth), and \\ Kenneth M.C. Cheung, MBBS, MD, FRCS, FHKCOS, FHKAM(Orth) \\ Investigation performed at the Department of Orthopaedics and Traumatology, University of Hong Kong, Hong Kong, SAR, China
}

\begin{abstract}
Background: Little is known regarding juvenile disc degeneration in individuals with normal spinal alignment. Consequently, the purpose of this study was to assess the prevalence, determinants, and clinical relevance associated with juvenile disc degeneration of the lumbar spine in individuals without spinal deformities.
\end{abstract}

Methods: A cross-sectional assessment of disc degeneration in juveniles was performed as part of a population-based study of 1989 Southern Chinese volunteers. Adolescents and young adults from thirteen to twenty years of age were defined as "juveniles." Juvenile subjects with no spinal deformity $(n=83)$ were stratified into two groups, those with and those without juvenile disc degeneration. Sagittal T2-weighted magnetic resonance images (MRI) were evaluated for the presence and extent of disc degeneration as well as other spinal findings. Demographics were assessed and clinical profiles were collected with use of standardized questionnaires.

Results: Juvenile disc degeneration was present in 35\% (twenty-nine) of the juveniles without spinal deformity. Disc bulging or extrusion $(p<0.001)$, high-intensity zones on MRI $(p=0.040)$, and greater weight $(p<0.001)$ and height $(p=$ 0.002 ) were significantly more prevalent in subjects with juvenile disc degeneration. Adjusted multivariate logistic regression modeling demonstrated that Asian-modified body-mass index (BMI) values in the overweight or obese range had a significant association with juvenile disc degeneration (odds ratio $=14.19 ; 95 \%$ confidence interval $=1.44$ to $140.40 ; p=0.023$ ). Overweight and obese individuals had greater severity of disc degeneration than underweight and normal-weight individuals $(p=0.036)$. Furthermore, individuals with juvenile disc degeneration had an increased prevalence of low back pain and/or sciatica $(p=0.002)$, greater low back pain intensity $(p<0.001)$, diminished social functioning $(p=0.049)$, and greater physical disability $(p<0.05)$ than individuals without disc degeneration. The $p$ value of $<0.05$ for physical disability represents both the physical function $(p=0.006)$ and the physical component $(p=$ 0.032 ) of the SF-36.

Conclusions: This study demonstrated that the presence of juvenile disc degeneration was strongly associated with overweight and obesity, low back pain, increased low back pain intensity, and diminished physical and social functioning. Furthermore, an elevated BMI was significantly associated with increased severity of disc degeneration. This study has public health implications regarding overweight and obesity and the development of lumbar disc disease.

Disclosure: In support of their research for or preparation of this work, one or more of the authors received, in any one year, outside funding or grants in excess of $\$ 10,000$ from the Area of Excellence Programme of Hong Kong. Neither they nor a member of their immediate families received payments or other benefits or a commitment or agreement to provide such benefits from a commercial entity.

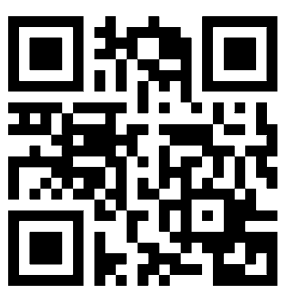

A commentary by Michael J. Bolesta, MD, is available at www.jbjs.org/commentary and is linked to the online version of this article. 
The Journal of Bone \& Joint Surgery $\cdot$ Jbjs.org

VOlume 93-A · Number 7 · April 6, 2011
Juvenile Disc Degeneration and Body-Mass Index

$\mathrm{L}$ ow back pain occurs in every population worldwide and has serious socioeconomic consequences ${ }^{1-3}$. Low back pain may affect daily function, diminish the quality of life, result in lost wages, increase health-care costs, and lead to psychological distress ${ }^{4-10}$. Several pathophysiological mechanisms exist that can account for low back pain ${ }^{4,11-13}$. Degeneration of the lumbar intervertebral disc is a major factor associated with low back pain ${ }^{9,14,15}$. In fact, the risk of developing low back pain increases with the severity of degenerative disc changes ${ }^{16}$.

Traditionally, disc degeneration has been attributed to the biochemical and structural alterations of the disc brought on by aging and excessive physical loading ${ }^{11,17-21}$. However, in recent years, additional factors contributing to disc degeneration have been reported, such as environmental determinants ${ }^{22-24}$, hormonal influences ${ }^{25,26}$, systemic diseases ${ }^{27-31}$, and genetic factors $^{22,32-40}$.

Although disc degeneration is predominantly a condition affecting adults, disc alterations have also been noted, although less commonly, in young individuals ${ }^{41-43}$. It has been suggested that disc degeneration in adolescents or in young adults less than twenty-one years old, referred to as juvenile disc degeneration, is highly associated with spinal deformities and vertebral end plate changes that alter the multidirectional biomechanical loads and stresses placed on the intervertebral segment, rendering the disc susceptible to degenerative changes $^{4-47}$. The prevalence of juvenile disc degeneration without spinal deformity remains unknown. These young individuals often present to their family physician or a rheumatologist with back pain and associated symptoms. This study was performed to assess the prevalence, determinants, and clinical relevance associated with juvenile disc degeneration in individuals without spinal deformity as compared with a control group of young individuals without disc degeneration of the lumbar spine.
TABLE I MRI Criteria for Disc Degeneration*

\begin{tabular}{|cl|}
\hline TABLE I MRI Criteria for Disc Degeneration* \\
\hline Grade & \multicolumn{1}{c|}{ Description } \\
\hline Normal & $\begin{array}{l}\text { No signal changes } \\
\text { Slight decrease in signal intensity of the nucleus } \\
\text { pulposus } \\
\text { Hypointense nucleus pulposus with normal } \\
\text { disc height } \\
\text { Hypointense nucleus pulposus with disc space } \\
\text { narrowing }\end{array}$ \\
\hline 3 &
\end{tabular}

*MRI criteria for disc degeneration based on T2-weighted sagittal MRI of the lumbar spine as described by Schneiderman et al. ${ }^{48}$.

\section{Materials and Methods Study Population}

ur study was a cross-sectional assessment of young individuals from thirteen to twenty years of age. Our sample was derived from a population of 1989 Southern Chinese volunteers (mean age, 39.4 years; range, 9.7 to eighty-eight years) as part of the Hong Kong Degenerative Disc Disease Cohort Study, a population-based initiative primarily designed to assess de-

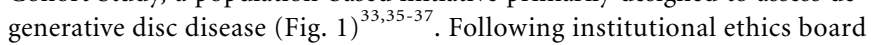
approval, our initial study population was recruited with use of an open regional invitation to approximately 7.6 million individuals to participate in a study of the spine with no predetermined inclusion criteria regarding the presence of back pain or any other symptoms. Radiographic and clinical questionnaire-based assessments were obtained for all individuals who agreed to participate, after they had provided informed consent. Exclusion criteria were an inflammatory condition of the spine, spinal tumor, spinal infection, known history of symptomatic vertebral fracture, previous lumbar spinal surgery, and lumbar deformity. In individuals who did not meet any of the exclusion criteria, and were between thirteen and twenty years old, we assessed the prevalence, determinants, and clinical factors associated with juvenile disc degeneration of the lumbar spine from L1 through S1. On the basis of the assessment, individuals were stratified into two groups, those with and those without juvenile disc degeneration.

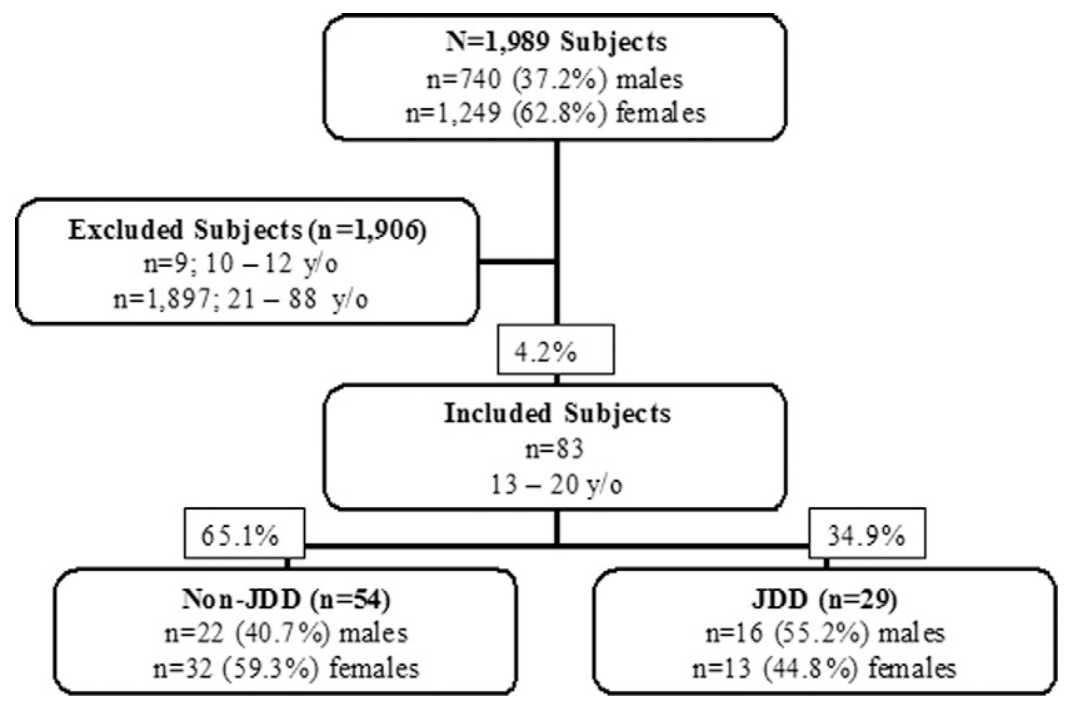

Fig. 1

Flow diagram illustrating the derivation of the sample sizes of the groups with and without juvenile disc degeneration (JDD). 


\section{TABLE II Association Between Disc Degeneration of the Lumbar Spine and Continuous Variables *}

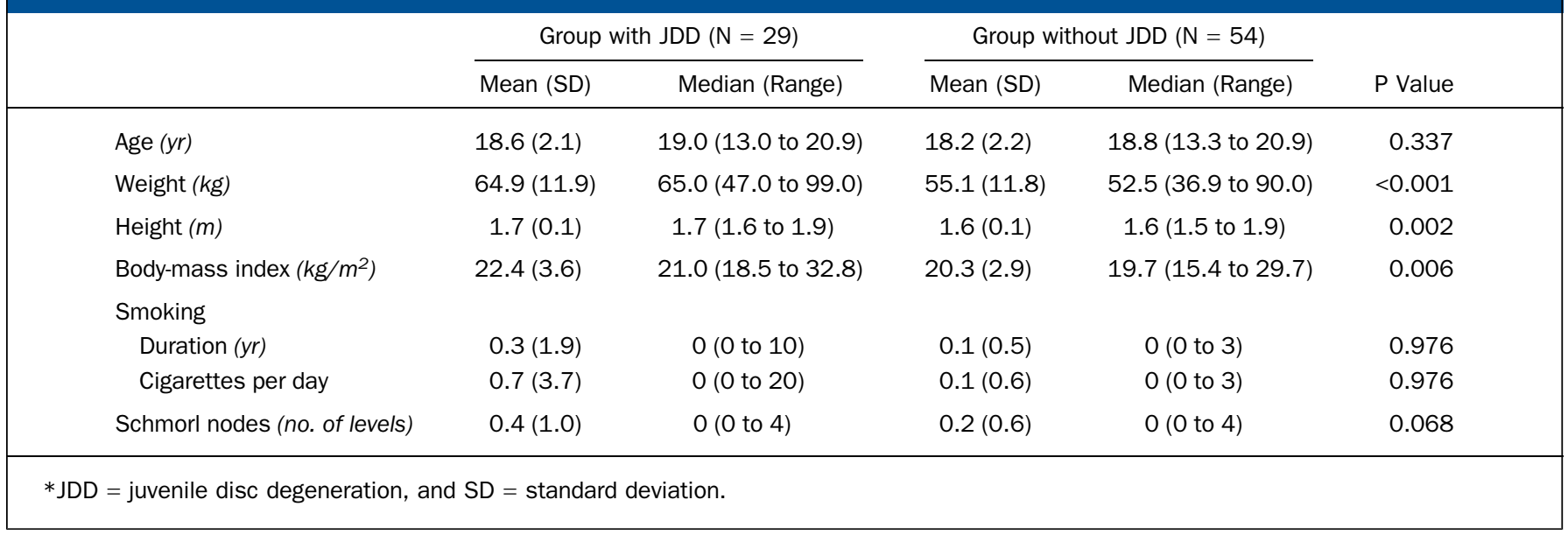

\section{Imaging Assessment}

Imaging assessment of all participants consisted of sagittal T2-weighted fastspin-echo magnetic resonance imaging (MRI) of the lumbar spine (TR, 3325 msec; TE, 85 msec; slice thickness, $5 \mathrm{~mm}$ ) with use of a 1.5-T clinical system $^{33,35}$. An individual blinded to the clinical assessment of the participants (J.K.) reviewed all MRIs. The findings of interest were the presence and extent of disc degeneration, disc bulges or extrusions, Schmorl nodes, high-intensity zones, and bone marrow changes. Disc degeneration was determined with use of the criteria established by Schneiderman et al. ${ }^{48}$ (Table I). Scores for segmental and overall degenerative disc disease of the lumbar spine were assigned for each individual, with a potential range from 0 to 15 for the overall score ${ }^{33,35}$. Disc bulging was defined as focal anular disruption of the disc material without violation of the posterior longitudinal ligament, whereas disc extrusion was defined as disc material that violated the posterior longitudinal ligament.

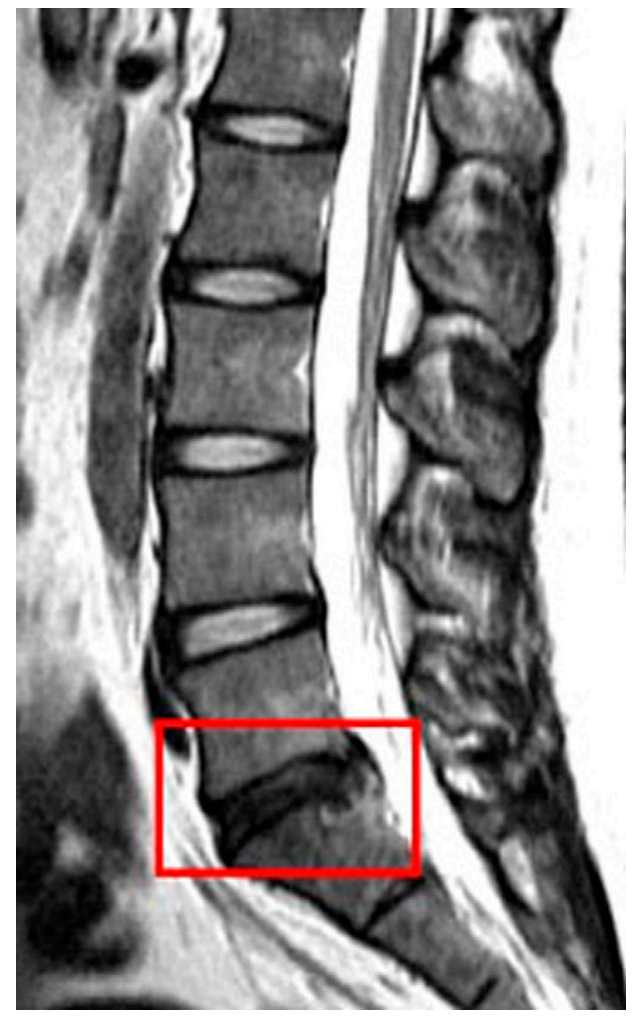

Fig. 2-A

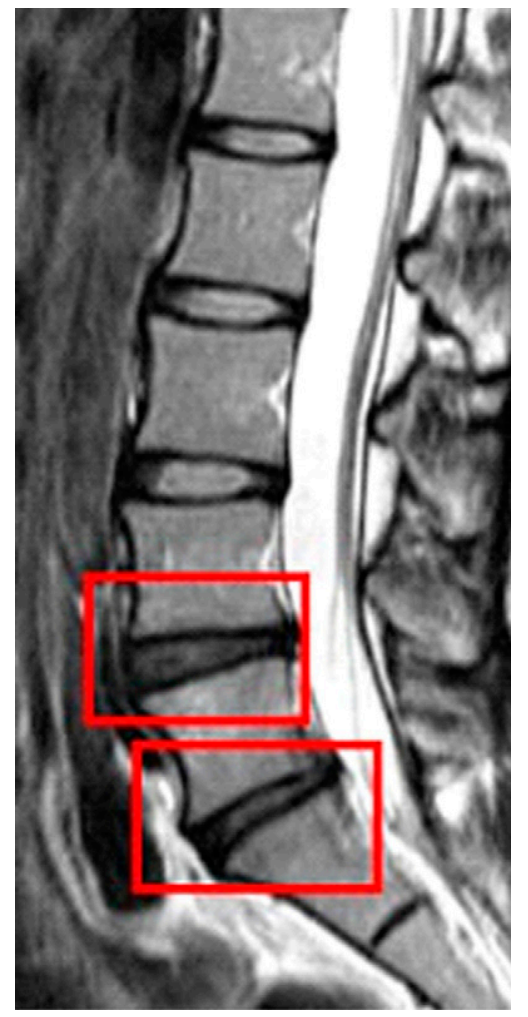

Fig. 2-B

Figs. 2-A and 2-B Sagittal T2-weighted magnetic resonance images of the lumbar spine illustrating disc degeneration. The boxes indicate the level of intervertebral disc degeneration. Fig. 2-A A twentyyear-old man with degeneration at a single level. Fig. 2-B A twenty-year-old woman with degeneration at two levels. 
An overall lumbar disc bulge or extrusion score was determined, with a potential range from 0 to 10 ; 0 points represented no disc bulge or extrusion, 1 point was assigned for each disc bulge, and 2 points were assigned for each disc extrusion. Schmorl nodes were defined as end plate abnormalities or irregularities with herniation of disc material into the cephalad and caudad end plates of the involved disc level. Bone marrow changes were defined as high signal intensities adjacent to the vertebral end plates ${ }^{2,49,50}$.

\section{Clinical Assessment}

Clinical assessment was performed with use of a subjective questionnaire, the Roland-Morris Questionnaire ${ }^{51}$, the Oswestry Disability Index ${ }^{52,53}$, and the Short Form-36 (SF-36) general lifestyle questionnaire ${ }^{54,55}$. Higher scores on the Roland-Morris Questionnaire and the Oswestry Disability Index indicate a worse condition, whereas lower scores on the SF-36 indicate a worse condition. Low back pain intensity was also assessed with use of a visual analog scale $^{56}$. Demographic data collected included age, weight, height, current or previous cigarette smoking and duration (in years) of cigarette smoking, exercise activity, and a history of lumbar injury. Overweight and obesity were defined as body-mass indices (BMIs) of 23 to $27.5 \mathrm{~kg} / \mathrm{m}^{2}$ and $>27.5 \mathrm{~kg} / \mathrm{m}^{2}$, respectively, based on the Asian-modified guidelines proposed by the World Health Organization ${ }^{57}$. Exercise activity was defined as active involvement in an exercise routine at least two times per week. A history of lumbar injury was defined as a traumatic event that had previously resulted in back pain. Subjects were also assessed for a history of low back pain, sciatica, and low back pain with sciatica. Low back pain was defined as continuous symptoms for two weeks or more, and sciatica was defined as pain radiating down one or both of the lower extremities beyond the knee and lasting for two weeks or more. To decrease the risk of recall bias in the assessment of these symptoms, a family member of the subject was consulted to assess the accuracy of the self-reporting.

\section{Statistical Analyses}

The data were coded for anonymity. Descriptive and frequency statistics were generated for all variables of interest. Chi-square or two-tailed Fisher exact tests were used as appropriate for categorical data. Mann-Whitney U and KruskalWallis $\mathrm{H}$ tests were used for continuous data analyzed in terms of two categories or more than two categories, respectively. Univariate logistic regression was performed to assess the association of each covariate with the presence of juvenile disc degeneration. All covariates with a $p$ value of $\leq 0.200$ in the univariate analysis were included in the subsequent multivariate logistic regression modeling, which produced an adjusted model of factors that were strongly predictive of, or associated with, the presence of juvenile disc degeneration. The Hosmer-Lemeshow goodness-of-fit test was used to assess the adequacy of the logistic regression model. The presence of collinearity and interaction effects was assessed. On the basis of the number of subjects included, the difference in the effect size for BMI between groups, and a threshold level of significance of $p=0.05$, the study had a $93.6 \%$ statistical power to prevent a Type-II error. The nominal level of significance was 0.05 , and $95 \%$ confidence intervals (CIs) were assessed to determine the strength and precision of the association.

\section{Source of Funding}

Funding was provided by the Area of Excellence (AoE) research program (AoE/ M-04/04) for Developmental Genomics and Skeletal Research at the University of Hong Kong.

\section{Results}

$\mathrm{C}$ ighty-three individuals met the inclusion criteria: fifty-four C (65\%; twenty-two males and thirty-two females) without juvenile disc degeneration and twenty-nine (35\%; sixteen males and thirteen females) with juvenile disc degeneration (Figs. 1, 2-A, and 2-B). The mean ages for subjects with and without juvenile disc degeneration were 18.6 and 18.2 years, respectively (Table II). With the numbers studied, there were no significant differences between the two groups with respect to sex $(\mathrm{p}=0.208)$ or age $(\mathrm{p}=0.337)$.

Significantly higher mean values for weight $(p<0.001)$, height $(p=0.002)$, and BMI $(p=0.006)$ were noted in the individuals with juvenile disc degeneration as compared with the individuals without juvenile disc degeneration (Table II). In addition, odds ratios and their respective $95 \%$ confidence intervals demonstrated an association between disc degeneration and weight, height, and BMI category (Table III). The presence of previous lumbar injury was noted in fourteen $(48 \%)$ and six $(11 \%)$ of the individuals with and without juvenile disc degeneration, respectively (Table IV), resulting in an odds ratio of 7.47 (95\% confidence interval, 2.44 to 22.85 ) for the presence of juvenile disc disease in individuals with previous lumbar injury (Table III). No significant association was noted between the presence or duration of cigarette smoking, exercise activity,

\begin{tabular}{|c|c|c|c|}
\hline Variable & $\begin{array}{l}\text { Odds } \\
\text { Ratio }\end{array}$ & $\begin{array}{c}95 \% \\
\text { Confidence } \\
\text { Interval }\end{array}$ & $P$ Value \\
\hline \multicolumn{4}{|l|}{ Sex } \\
\hline Female & 1 & & \\
\hline Male & 1.79 & $0.72-4.45$ & 0.208 \\
\hline \multicolumn{4}{|l|}{ Weight* (kg) } \\
\hline$<49.0$ & 1 & & \\
\hline $49.0-55.0$ & 3.19 & $0.56-18.16$ & 0.192 \\
\hline $55.1-65.3$ & 4.86 & $0.88-26.68$ & 0.069 \\
\hline$>65.3$ & 15.79 & $2.80-88.99$ & 0.002 \\
\hline \multicolumn{4}{|l|}{ Height* $(m)$} \\
\hline$<1.60$ & 1 & & \\
\hline $1.60-1.65$ & 1.62 & $0.21-8.48$ & 0.568 \\
\hline $1.66-1.72$ & 4.64 & $1.02-21.00$ & 0.047 \\
\hline$>1.72$ & 6.14 & $1.43-26.35$ & 0.015 \\
\hline \multicolumn{4}{|c|}{ Body-mass index $\dagger\left(\mathrm{kg} / \mathrm{m}^{2}\right)$} \\
\hline Underweight & 1 & & \\
\hline Normal & 12.00 & $1.47-98.01$ & 0.020 \\
\hline Overweight or obese & 20.00 & $2.20-181.56$ & 0.008 \\
\hline \multicolumn{4}{|l|}{ Cigarette smoker } \\
\hline No & 1 & & \\
\hline Yes & 0.93 & $0.08-10.70$ & 0.953 \\
\hline \multicolumn{4}{|l|}{ Exercise activity } \\
\hline No & 1 & & \\
\hline Yes & 1.58 & $0.57-4.35$ & 0.379 \\
\hline \multicolumn{4}{|l|}{ Previous lumbar injury } \\
\hline No & 1 & & \\
\hline Yes & 7.47 & $2.44-22.85$ & $<0.001$ \\
\hline \multicolumn{4}{|l|}{ Schmorl nodes } \\
\hline No & 1 & & \\
\hline Yes & 3.26 & $0.84-12.68$ & 0.088 \\
\hline
\end{tabular}

*The weight and height categories were based on quartiles in the overall group. †The body-mass index categories were based on the Asian-modified World Health Organization guidelines defining underweight $\left(<18.5 \mathrm{~kg} / \mathrm{m}^{2}\right)$, normal $\left(18.5-23.0 \mathrm{~kg} / \mathrm{m}^{2}\right)$, and overweight/obese $\left(>23.0 \mathrm{~kg} / \mathrm{m}^{2}\right)$. 


\begin{tabular}{|lccc|}
\hline \multicolumn{1}{c}{ Variable } & \multicolumn{2}{c|}{ Cases (no.[\%]) } & P Value \\
\cline { 2 - 3 } & Group with JDD $(\mathrm{N}=29)$ & Group without JDD (N = 54) & 0.208 \\
Sex (male) & $16(55)$ & $22(41)$ & 0.953 \\
Cigarette smoker & $1(3)$ & $2(4)$ & 0.379 \\
Exercise activity & $9(31)$ & $12(22)$ & $<0.001$ \\
Previous lumbar injury & $14(48)$ & $6(11)$ & $<0.001$ \\
Disc bulge/extrusion & $19(66)$ & $0(0)$ & 0.040 \\
HIZ & $3(10)$ & $0(0)$ & 0.349 \\
Bone marrow changes & $1(3)$ & $0(0)$ & 0.088 \\
Schmorl nodes & $6(21)$ & $4(7)$ & \\
\hline *JDD $=$ juvenile disc degeneration, and HIZ $=$ high-intensity zones. & & \\
\hline
\end{tabular}

or the presence of Schmorl nodes and juvenile disc degeneration ( $\mathrm{p}>0.05)$ (Tables III and IV).

No individual without juvenile disc degeneration had any disc bulge or extrusion, high-intensity zone, or bone marrow changes. In contrast, nineteen $(66 \%)$ of the individuals with juvenile disc degeneration had a disc bulge or extrusion $(\mathrm{p}<$ $0.001)$, three $(10 \%)$ had a high-intensity zone $(\mathrm{p}=0.040)$, and one $(3 \%)$ had bone marrow changes $(\mathrm{p}=0.349)$ (Table IV).

Subjects with juvenile disc disease had a mean of 1.3 levels (range, one to three levels) of disc degeneration, a mean overall degenerative disc disease score of 2.9 (range, 1 to 9), and a mean overall disc bulge or extrusion score of 1 (range, 0 to 3 ). Twenty (69\%) had single-level disc degeneration, and nine (31\%) had multilevel degeneration (six with two levels and three with three levels). With the numbers studied, there was no significant association between the number of levels of disc degeneration and age $(p=0.337)$. In addition, there were no significant associations between the number of levels of disc degeneration in subjects with juvenile disc degeneration and weight $(\mathrm{p}=0.379)$, height $(\mathrm{p}=0.490)$, BMI $(\mathrm{p}=0.835)$, or previous lumbar injury $(\mathrm{p}=0.700)$.

Elevated BMIs were significantly correlated with an increase in overall disc degeneration severity as measured with use of the degenerative disc disease score $(r=0.300 ; p=0.005)$. Overweight and obese individuals had significantly higher mean overall degenerative disc disease scores than underweight and normal-weight individuals (mean and standard deviation, $1.8 \pm$ 2.4 [range, 0 to 9] compared with $0.78 \pm 1.5$ [range, 0 to 6 ]; $\mathrm{p}=$ 0.036 ). On the basis of multivariate logistic regression modeling, overweight or obesity (adjusted odds ratio, 14.19; 95\% confidence interval, 1.44 to $140.40 ; \mathrm{p}=0.023$ ) and previous lumbar injury (adjusted odds ratio, 6.57; 95\% confidence interval, 1.96 to $22.02 ; \mathrm{p}=0.002$ ) were strongly associated with the presence of juvenile disc degeneration (Table V).

Overall, sixty individuals (72\%) had low back pain and twenty-six $(31 \%)$ had sciatica; twenty-four of these individuals ( $29 \%$ of the study group) had both low back pain and sciatica. In the group without juvenile disc degeneration, thirty-three
(61\%), ten (19\%), and eight (15\%) had low back pain, sciatica, and low back pain with sciatica, respectively (Fig. 3). The prevalence of these symptoms was significantly higher in the group with juvenile disc degeneration, in which twenty-seven $(93 \% ; p=0.002)$, sixteen $(55 \% ; p=0.001)$, and sixteen $(55 \%$; $\mathrm{p}<0.001$ ) had low back pain, sciatica, and low back pain with sciatica, respectively (Fig. 3). Sex, weight, height, BMI, exercise status, smoking, high-intensity zones, bone marrow changes, disc bulge or extrusion, and multilevel disc degeneration were not found to be significantly related to the presence of symptoms in the juvenile disc degeneration group $(p>0.05)$. However, previous injury to the lumbar spine was found to be significantly associated with sciatica $(\mathrm{p}=0.014)$ and with low back pain with sciatica $(\mathrm{p}=0.014)$ in individuals with juvenile disc degeneration. Sex, weight, height, BMI, exercise status, and smoking were not found to be significantly associated with symptoms in individuals without juvenile disc degeneration $(\mathrm{p}>0.05)$.

\begin{tabular}{|c|c|c|}
\hline \multicolumn{3}{|c|}{$\begin{array}{l}\text { TABLE V Adjusted Multivariate Logistic Regression Model } \\
\text { for the Presence of Disc Degeneration of the } \\
\text { Lumbar Spine* }\end{array}$} \\
\hline Factor & $\begin{array}{c}\text { Adjusted Odds } \\
\text { Ratio (95\% Confidence } \\
\text { Interval) }\end{array}$ & P Value \\
\hline \multicolumn{3}{|l|}{ Body-mass index $\dagger$} \\
\hline Underweight & 1 & \\
\hline Normal & $11.70(1.34-102.37)$ & 0.026 \\
\hline Overweight/obese & $14.19(1.44-140.40)$ & 0.023 \\
\hline Previous lumbar injury & $6.57(1.96-22.02)$ & 0.002 \\
\hline \multicolumn{3}{|c|}{$\begin{array}{l}\text { *Hosmer and Lemeshow goodness-of-fit chi-square } p=0.400 \text {, } \\
\text { and Nagelkerke } R^{2}=0.335 \text {. †The body-mass index categories } \\
\text { were based on Asian-modified World Health Organization guide- } \\
\text { lines defining underweight }\left(<18.5 \mathrm{~kg} / \mathrm{m}^{2}\right) \text {, normal }\left(18.5-23.0 \mathrm{~kg} / \mathrm{m}^{2}\right) \text {, } \\
\text { and overweight/obese }\left(>23.0 \mathrm{~kg} / \mathrm{m}^{2}\right) .\end{array}$} \\
\hline
\end{tabular}




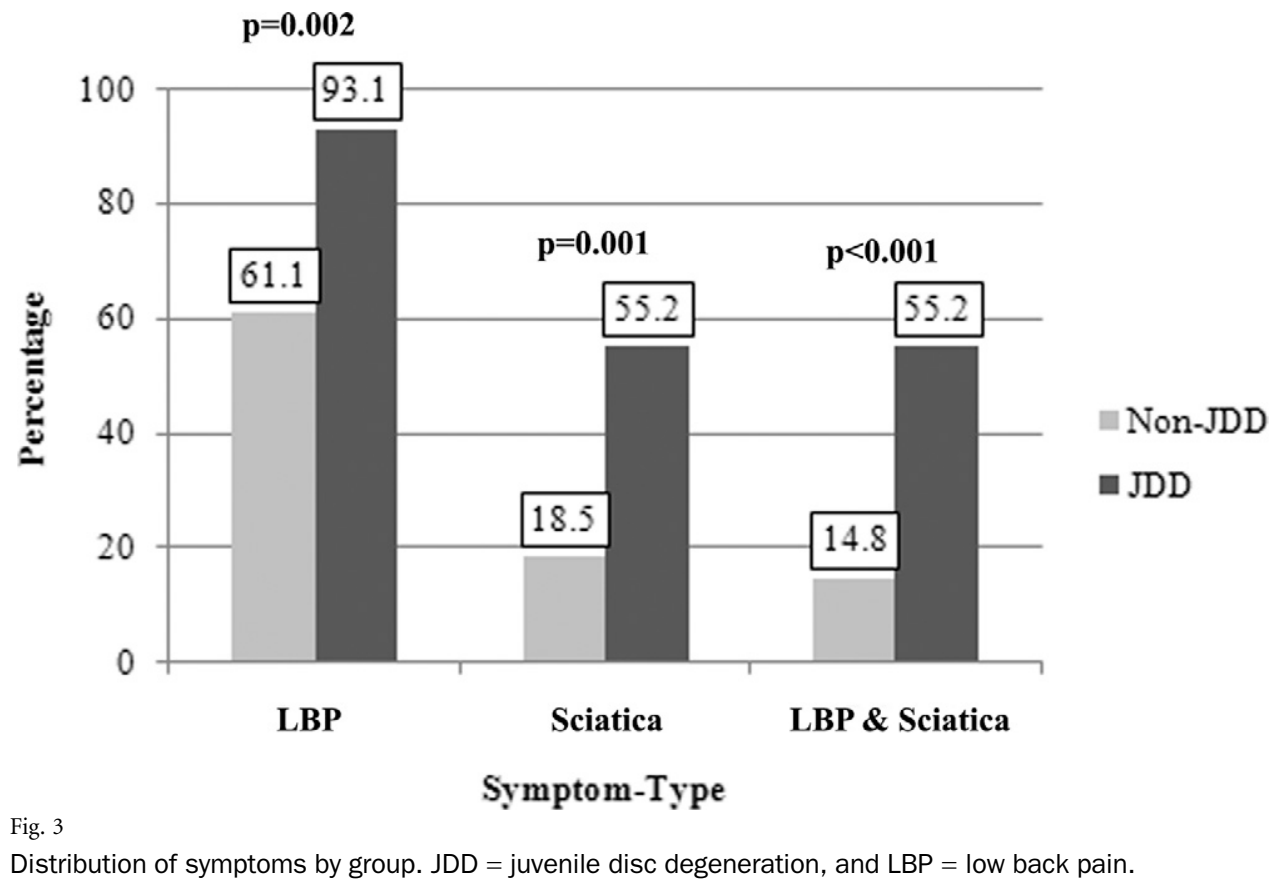

With regard to functional outcome, individuals with juvenile disc degeneration reported a greater severity of lumbar pain with use of the visual analog scale assessment than did individuals without juvenile disc degeneration (mean and standard deviation, $65.5 \pm 27.9$ [range, 16 to 100] compared with $37.5 \pm 33.3$ [range, 0 to 100]; $\mathrm{p}<0.001$ ). Although there was no significant difference between the groups with regard to the Roland-Morris disability assessment (mean, 2.7 and 2.0 in the groups with and without juvenile disc degeneration, respectively; $\mathrm{p}=0.166$ ), the Oswestry Disability Index for individuals with juvenile disc degeneration (11.4 \pm 14.3 ; range, 0 to 56) was significantly higher than that for individuals without juvenile disc degeneration $(5.6 \pm 10.7$; range, 0 to 49$)(\mathrm{p}=$ 0.005 ), reflecting the marginal disability related to daily activities experienced by subjects with juvenile disc degeneration. On the SF-36, individuals with juvenile disc degeneration reported a greater degree of bodily pain than did those without degeneration (64.3 compared with $72.5 ; \mathrm{p}=0.069)$, worse overall physical function (84.1 compared with 91.5; $\mathrm{p}=0.006)$ and physical status (46.5 compared with $50.6 ; \mathrm{p}=0.032$ ), and poorer social functioning (78.9 compared with 85.2; $\mathrm{p}=0.049$ ).

\section{Discussion}

Tuvenile disc degeneration occurred in 35\% (twenty-nine) of our subjects between thirteen and twenty years of age. While the prevalence of juvenile disc degeneration was not high in the general population, the large size of our cohort permitted us to address the various factors associated with such degeneration. Multivariate logistic regression modeling showed elevated BMI values to be strongly associated with disc degeneration. In fact, individuals regarded as overweight or obese had a fourteenfold greater prevalence of disc degeneration than underweight and normal-weight individuals. Although the confidence interval for this odds ratio was broad as a result of our sample size, the association of BMI with disc degeneration was significant, and the confidence interval should narrow with an increased sample size. Overall, mean values of weight, height, and BMI were significantly higher in individuals with disc degeneration than in those without. Furthermore, individuals who were overweight or obese presented with significantly greater overall severity of disc degeneration of the lumbar spine than did underweight and normal-weight individuals.

Disc degeneration is associated with biochemical changes in the extracellular matrix, with local inflammatory responses leading to structural changes in the disc and subsequent modification of biomechanical forces applied to the intervertebral segment that may further promote disc degeneration ${ }^{11,58-60}$. However, the exact mechanism by which obesity relates to disc degeneration is not well understood. According to $\mathrm{Das}^{61}$, the condition of overweight or obesity is an inflammatory disorder associated with increased serum levels of interleukin-6, C-reactive protein, tumor necrosis factor $\alpha$, and leptin. Such findings have been identified as risk factors for cardiovascular disease, which in turn may induce inflammatory responses in the disc as well as affect blood circulation in the spine and alter metabolite and nutrient flow from the end plate to the $\operatorname{disc}^{27-31,62-65}$.

To a lesser degree than the factors of overweight or obesity in our study, multivariate logistic regression modeling showed that a history of lumbar injury was associated with disc degeneration. In an investigation of the effects of occupational hazards on the development of disc degeneration, Luoma et al. ${ }^{18}$ noted that "accidental back injuries" were highly associated with disc degeneration. Carragee et al. ${ }^{66}$ contended that minor back injuries may not lead to disc degeneration or back pain, but rather demographic and behavioral factors may account for low back pain events. According to Möller et al. ${ }^{67}$, back injuries may 
The Journal of Bone \& Joint Surgery $\cdot$ Jbjs.org

VOlume 93-A · Number 7 · April 6, 2011
Juvenile Disc Degeneration and Body-Mass Index

However, the study provides information regarding the severity of the impact that behavioral or demographic variables may have on disc degeneration. Our sample group was composed of young Southern Chinese individuals, so generalizations to other populations should be further verified. Nonetheless, to our knowledge, our study is the first to address disc degeneration in young Chinese individuals. Also, the overall prevalence of disc degeneration in this population echoes those in studies from Western countries ${ }^{41-47,68}$. Our methods and assessment tools are known to be reliable and are commonly used in Western countries. As a result of costs, our imaging assessment was limited to sagittal T2-weighted magnetic resonance images. Nonetheless, sagittal T2-weighted magnetic resonance images have been noted to be a reliable and accurate modality for assessing disc degeneration in the lumbar spine $e^{2,48,69-72}$. Furthermore, in an effort to assess the reliability of our image interpretations, we performed post hoc analyses of the initial 1689 cases following completion of our study. The interpretations of a second independent observer (K.M.C.C.), blinded to previous imaging and clinical findings, resulted in an interobserver agreement of up to $98 \%$, reflecting overall good to excellent interobserver reliability ${ }^{73}$.

Appropriate lifestyle modifications, such as developing healthy eating habits and a proper exercise regimen, should be considered in order to decrease the risk of developing disc degeneration at a young age. The development of juvenile disc degeneration may contribute to several adult spinal conditions $s^{74,75}$. Preventative measures should be considered to avoid early-onset disc degeneration that may have negative physical, social, and economic implications affecting younger generations worldwide.

Note: The authors wish to thank Dr. Danny Chan, Prof. Kathy Cheah, and Mrs. Yu Pei of the Department of Biochemistry at the University of Hong Kong, Hong Kong, SAR, China, for their assistance with this study.

symptoms. Furthermore, disc bulges or extrusions were found only in individuals with juvenile disc degeneration. With the numbers studied, we were unable to determine an association between age or other demographic variables and symptoms.

Numerous studies using validated quality-of-life outcome tools have demonstrated significantly greater low back pain intensity and functional disability and significantly diminished social functioning in individuals with juvenile disc degeneration than in those without. If the degeneration is left untreated, it will continue to have deleterious effects on the quality of life of an individual. The implications of early deterioration or impairment of physical and social functioning associated with disc degeneration in such a young population are of global concern. Furthermore, disc degeneration that begins at an earlier age will have a greater impact on various quality-of-life measures.

Although our study was able to address the prevalence, associated factors, and clinical relevance of juvenile disc degeneration, it had some limitations. Because of the nature of our study design, it was not possible to assess the time-to-event course for various events or exposures or to assess the role of various other factors pertaining to the development of disc degeneration and symptoms. Consequently, conclusions regarding associations, but not regarding causality, can be drawn.
Dino Samartzis, DSc

Florence Mok, MSc

Keith D.K. Luk, MCh(Orth), FRCSE, FRCSG, FRACS, FHKAM(Orth) Kenneth M.C. Cheung, MBBS, MD, FRCS, FHKCOS, FHKAM(Orth)

Department of Orthopaedics and Traumatology,

University of Hong Kong, Queen Mary Hospital, Professorial Block,

Fifth Floor, 102 Pokfulam Road, Pokfulam,

Hong Kong, SAR, China.

E-mail address for D. Samartzis: dsamartzis@msn.com.

E-mail address for K.M.C. Cheung: ken-cheung@hku.hk

Jaro Karppinen, MD, $\mathrm{PhD}$

Department of Physical and Rehabilitation Medicine,

Institute of Clinical Sciences, University of Oulu,

Box 5000, 90014 Oulu, Finland

Daniel Y.T. Fong, $\mathrm{PhD}$

School of Nursing, University of Hong Kong,

William M.W. Mong Block,

Li Ka Shing Faculty of Medicine Building,

Third Floor, 21 Sassoon Road, Pokfulam,

Hong Kong, SAR, China 


\section{References}

1. Coste J, Paolaggi JB, Spira A. Reliability of interpretation of plain lumbar spine radiographs in benign, mechanical low-back pain. Spine (Phila Pa 1976). 1991;16: 426-8.

2. Modic MT, Pavlicek W, Weinstein MA, Boumphrey F, Ngo F, Hardy R, Duchesneau $\mathrm{PM}$. Magnetic resonance imaging of intervertebral disk disease. Clinical and pulse sequence considerations. Radiology. 1984;152:103-11.

3. Kelsey JL. Epidemiology of musculoskeletal disorders. New York: Oxford Univ Pr; 1982.

4. Andersson GB. Epidemiological features of chronic low-back pain. Lancet. 1999; 354:581-5.

5. Deyo RA, Tsui-Wu YJ. Descriptive epidemiology of low-back pain and its related medical care in the United States. Spine (Phila Pa 1976). 1987;12:264-8.

6. Hart LG, Deyo RA, Cherkin DC. Physician office visits for low back pain. Frequency, clinical evaluation, and treatment patterns from a U.S. national survey. Spine (Phila Pa 1976). 1995;20:11-9.

7. Dagenais S, Caro J, Haldeman S. A systematic review of low back pain cost of illness studies in the United States and internationally. Spine J. 2008;8:8-20.

8. Ekman M, Jönhagen S, Hunsche E, Jönsson L. Burden of illness of chronic low back pain in Sweden: a cross-sectional, retrospective study in primary care setting Spine (Phila Pa 1976). 2005;30:1777-85.

9. Luoma K, Riihimäki H, Luukkonen R, Raininko R, Viikari-Juntura E, Lamminen A. Low back pain in relation to lumbar disc degeneration. Spine (Phila Pa 1976). 2000;25:487-92.

10. Wenig CM, Schmidt CO, Kohlmann T, Schweikert B. Costs of back pain in Germany. Eur J Pain. 2009;12:280-6.

11. Adams MA, Freeman BJ, Morrison HP, Nelson IW, Dolan P. Mechanical initiation of intervertebral disc degeneration. Spine (Phila Pa 1976). 2000;25:1625-36.

12. Raj PP. Intervertebral disc: anatomy-physiology-pathophysiology-treatment. Pain Pract. 2008;8:18-44.

13. Yong-Hing $\mathrm{K}$, Kirkaldy-Willis $\mathrm{WH}$. The pathophysiology of degenerative disease of the lumbar spine. Orthop Clin North Am. 1983;14:491-504.

14. Borenstein DG, O'Mara JW Jr, Boden SD, Lauerman WC, Jacobson A, Platenberg $C$, Schellinger D, Wiesel SW. The value of magnetic resonance imaging of the lumbar spine to predict low-back pain in asymptomatic subjects: a seven-year follow-up study. J Bone Joint Surg Am. 2001;83:1306-11.

15. de Schepper El, Damen J, van Meurs JB, Ginai AZ, Popham M, Hofman A, Koes BW, Bierma-Zeinstra SM. The association between lumbar disc degeneration and low back pain: the influence of age, gender, and individual radiographic features. Spine (Phila Pa 1976). 2010;35:531-6.

16. Samartzis D, Karppinen J, Chan D, Luk KDK, Cheung KM. The association of disc degeneration based on magnetic resonance imaging and the presence of low back pain. Presented at the World Forum for Spine Research: Intervertebral Disc; Montreal; 2010 Jul 5-8.

17. Boos N, Weissbach S, Rohrbach H, Weiler C, Spratt KF, Nerlich AG. Classification of age-related changes in lumbar intervertebral discs: 2002 Volvo Award in basic science. Spine (Phila Pa 1976). 2002;27:2631-44.

18. Luoma K, Riihimäki H, Raininko R, Luukkonen R, Lamminen A, Viikari-Juntura $E$. Lumbar disc degeneration in relation to occupation. Scand J Work Environ Health. 1998;24:358-66.

19. Nerlich AG, Schleicher ED, Boos N. 1997 Volvo Award winner in basic science studies. Immunohistologic markers for age-related changes of human lumbar intervertebral discs. Spine (Phila Pa 1976). 1997;22:2781-95.

20. Videman $T$, Nurminen $M$. The occurrence of anular tears and their relation to lifetime back pain history: a cadaveric study using barium sulfate discography. Spine (Phila Pa 1976). 2004;29:2668-76.

21. Videman T, Nurminen M, Troup JD. 1990 Volvo Award in clinical sciences. Lumbar spinal pathology in cadaveric material in relation to history of back pain occupation, and physical loading. Spine (Phila Pa 1976). 1990;15:728-40. 22. Battié MC, Videman T, Gill K, Moneta GB, Nyman R, Kaprio J, Koskenvuo M. 1991 Volvo Award in clinical sciences. Smoking and lumbar intervertebral disc degeneration: an MRI study of identical twins. Spine (Phila Pa 1976). 1991;16:1015-21.

23. Battié MC, Videman T, Gibbons LE, Fisher LD, Manninen H, Gill K. 1995 Volvo Award in clinical sciences. Determinants of lumbar disc degeneration. A study relating lifetime exposures and magnetic resonance imaging findings in identical twins. Spine (Phila Pa 1976). 1995;20:2601-12.

24. Hangai M, Kaneoka K, Kuno S, Hinotsu S, Sakane M, Mamizuka N, Sakai S, Ochiai N. Factors associated with lumbar intervertebral disc degeneration in the elderly. Spine J. 2008;8:732-40.

25. Miller JA, Schmatz C, Schultz AB. Lumbar disc degeneration: correlation with age, sex, and spine level in 600 autopsy specimens. Spine (Phila Pa 1976). 1988; 13:173-8.

26. Skrzypiec D, Tarala M, Pollintine $P$, Dolan $P$, Adams MA. When are intervertebral discs stronger than their adjacent vertebrae? Spine (Phila Pa 1976). 2007;32: 2455-61.
27. Leino-Arjas $P$, Kaila-Kangas $L$, Solovieva $S$, Riihimäki $H$, Kirjonen J, Reunanen $A$ Serum lipids and low back pain: an association? A follow-up study of a working population sample. Spine (Phila Pa 1976). 2006;31:1032-7.

28. Leino-Arjas $P$, Solovieva S, Kirjonen J, Reunanen A, Riihimäki H. Cardiovascular risk factors and low-back pain in a long-term follow-up of industrial employees. Scand J Work Environ Health. 2006;32:12-9.

29. Shiri R, Karppinen J, Leino-Arjas $P$, Solovieva S, Varonen H, Kalso E, Ukkola O, Viikari-Juntura E. Cardiovascular and lifestyle risk factors in lumbar radicular pain or clinically defined sciatica: a systematic review. Eur Spine J. 2007;16:2043-54.

30. Kauppila LI, McAlindon T, Evans S, Wilson PW, Kiel D, Felson DT. Disc degeneration/back pain and calcification of the abdominal aorta. A 25-year follow-up study in Framingham. Spine (Phila Pa 1976). 1997;22:1642-9.

31. Turgut AT, Sönmez I, Cakıt BD, Koşar P, Koşar U. Pineal gland calcification, lumbar intervertebral disc degeneration and abdominal aorta calcifying atherosclerosis correlate in low back pain subjects: a cross-sectional observational CT study. Pathophysiology. 2008;15:31-9

32. Chan D, Song Y, Sham $P$, Cheung KM. Genetics of disc degeneration. Eur Spine J. 2006;15 Suppl 3:S317-25.

33. Cheung KM, Chan D, Karppinen J, Chen Y, Jim JJ, Yip SP, Ott J, Wong KK, Sham $P$, Luk KD, Cheah KS, Leong JC, Song YQ. Association of the Taq I allele in vitamin D receptor with degenerative disc disease and disc bulge in a Chinese population. Spine (Phila Pa 1976). 2006;31:1143-8.

34. Cheung KM, Samartzis D, Karppinen J, Mok FP, Ho DW, Fong DY, Luk KD. Intervertebral disc degeneration: new insights based on "skipped" level disc pathology. Arthritis Rheum. 2010;62:2392-400.

35. Jim JJ, Noponen-Hietala N, Cheung KM, Ott J, Karppinen J, Sahraravand A, LuK KD, Yip SP, Sham PC, Song YQ, Leong JC, Cheah KS, Ala-Kokko L, Chan D. The TRP2 allele of COL9A2 is an age-dependent risk factor for the development and severity of intervertebral disc degeneration. Spine (Phila Pa 1976). 2005;30:2735-42.

36. Song YQ, Cheung KM, Ho DW, Poon SC, Chiba K, Kawaguchi Y, Hirose Y, Alini M, Grad S, Yee AF, Leong JC, Luk KD, Yip SP, Karppinen J, Cheah KS, Sham P, Ikegawa $\mathrm{S}$, Chan D. Association of the asporin D14 allele with lumbar-disc degeneration in Asians. Am J Hum Genet. 2008;82:744-7.

37. Song YQ, Ho DW, Karppinen J, Kao PY, Fan BJ, Luk KD, Yip SP, Leong JC, Cheah KS, Sham P, Chan D, Cheung KM. Association between promoter -1607 polymorphism of MMP1 and lumbar disc disease in Southern Chinese. BMC Med Genet. 2008;9:38.

38. Virtanen IM, Song YQ, Cheung KM, Ala-Kokko L, Karppinen J, Ho DW, Luk KD, Yip SP, Leong JC, Cheah KS, Sham P, Chan D. Phenotypic and population differences in the association between CILP and lumbar disc disease. J Med Genet. 2007;44:285-8.

39. Battié MC, Haynor DR, Fisher LD, Gill K, Gibbons LE, Videman T. Similarities in degenerative findings on magnetic resonance images of the lumbar spines of identical twins. J Bone Joint Surg Am. 1995;77:1662-70

40. Sambrook PN, MacGregor AJ, Spector TD. Genetic influences on cervical and lumbar disc degeneration: a magnetic resonance imaging study in twins. Arthritis Rheum. 1999;42:366-72.

41. Paajanen $H$, Erkintalo $M$, Kuusela $T$, Dahlstrom $S$, Kormano M. Magnetic resonance study of disc degeneration in young low-back pain patients. Spine (Phila Pa 1976). 1989;14:982-5.

42. Heithoff KB, Gundry CR, Burton CV, Winter RB. Juvenile discogenic disease. Spine (Phila Pa 1976). 1994;19:335-40.

43. Swischuk LE, John SD, Allbery S. Disk degenerative disease in childhood: Scheuermann's disease, Schmorl's nodes, and the limbus vertebra: MRI findings in 12 patients. Pediatr Radiol. 1998;28:334-8

44. Erkintalo MO, Salminen JJ, Alanen AM, Paajanen HE, Kormano MJ. Development of degenerative changes in the lumbar intervertebral disk: results of a prospective MR imaging study in adolescents with and without low-back pain. Radiology. 1995;196:529-33.

45. Khoury NJ, Hourani MH, Arabi MM, Abi-Fakher F, Haddad MC. Imaging of back pain in children and adolescents. Curr Probl Diagn Radiol. 2006;35:224-44.

46. Paajanen $H$, Alanen A, Erkintalo M, Salminen JJ, Katevuo K. Disc degeneration in Scheuermann disease. Skeletal Radiol. 1989;18:523-6.

47. Cleveland RH, Delong GR. The relationship of juvenile lumbar disc disease and Scheuermann's disease. Pediatr Radiol. 1981;10:161-4.

48. Schneiderman $G$, Flannigan $B$, Kingston $S$, Thomas J, Dillin WH, Watkins RG Magnetic resonance imaging in the diagnosis of disc degeneration: correlation with discography. Spine (Phila Pa 1976). 1987;12:276-81.

49. Modic MT, Masaryk TJ, Ross JS, Carter JR. Imaging of degenerative disk disease. Radiology. 1988;168:177-86.

50. Modic MT, Steinberg PM, Ross JS, Masaryk TJ, Carter JR. Degenerative disk disease: assessment of changes in vertebral body marrow with MR imaging. Radiology. 1988;166:193-9.

51. Roland M, Fairbank J. The Roland-Morris Disability Questionnaire and the Oswestry Disability Questionnaire. Spine (Phila Pa 1976). 2000;25:3115-24. 
The Journal of Bone \& Joint Surgery $\cdot$ Jbjs.org Volume 93-A • Number $7 \cdot$ April 6, 2011

52. Fairbank JC, Couper J, Davies JB, O’Brien JP. The Oswestry low back pain disability questionnaire. Physiotherapy. 1980;66:271-3.

53. Fairbank JC, Pynsent PB. The Oswestry Disability Index. Spine (Phila Pa 1976). 2000;25:2940-52.

54. Samartzis D, Dominique DA, Perez-Cruet MJ, Fehlings MG. Clinical outcome analyses. In: Perez-Cruet MJ, Khoo LT, Fessler RG, editors. An anatomical approach to minimally invasive spine surgery. St. Louis: Quality Medical Publishing, Inc; 2006. p 103-30.

55. Ware JE Jr, Sherbourne CD. The MOS 36-item short-form health survey (SF-36). I. Conceptual framework and item selection. Med Care. 1992;30:473-83.

56. Haefeli M, Elfering A. Pain assessment. Eur Spine J. 2006;15 Suppl 1:

S17-24.

57. Obesity: preventing and mapping the global epidemic. Geneva: World Health Organization; 1997.

58. Fujiwara A, Lim TH, An HS, Tanaka N, Jeon CH, Andersson GB, Haughton VM. The effect of disc degeneration and facet joint osteoarthritis on the segmental flexibility of the lumbar spine. Spine (Phila Pa 1976). 2000;25:3036-44.

59. Fujiwara A, Tamai K, An HS, Kurihashi T, Lim TH, Yoshida H, Saotome K. The relationship between disc degeneration, facet joint osteoarthritis, and stability of the degenerative lumbar spine. J Spinal Disord. 2000;13:444-50.

60. Tanaka N, An HS, Lim TH, Fujiwara A, Jeon CH, Haughton VM. The relationship between disc degeneration and flexibility of the lumbar spine. Spine J. 2001:1:47-56.

61. Das UN. Is obesity an inflammatory condition? Nutrition. 2001;17:953-66.

62. Kauppila LI. Blood supply of the lower thoracic and lumbosacral regions. Postmortem aortography in 38 young adults. Acta Radiol. 1994;35:541-4.

63. Kauppila LI. Ingrowth of blood vessels in disc degeneration. Angiographic and histological studies of cadaveric spines. J Bone Joint Surg Am. 1995;77: 26-31.

64. Kauppila LI. Can low-back pain be due to lumbar-artery disease? Lancet. 1995; 346:888-9.
Juvenile Disc Degeneration and Body-Mass Index

65. Kauppila LI, Penttilä A, Karhunen PJ, Lalu K, Hannikainen P. Lumbar disc degeneration and atherosclerosis of the abdominal aorta. Spine (Phila Pa 1976). 1994;19:923-9.

66. Carragee E, Alamin T, Cheng I, Franklin T, Hurwitz E. Does minor trauma cause serious low back illness? Spine (Phila Pa 1976). 2006;31:2942-9.

67. Möller A, Maly P, Besjakov J, Hasserius R, Ohlin A, Karlsson MK. A vertebral fracture in childhood is not a risk factor for disc degeneration but for Schmorl's nodes: a mean 40-year observational study. Spine (Phila Pa 1976). 2007;32:2487-92.

68. Salo S, Paajanen $\mathrm{H}$, Alanen A. Disc degeneration of pediatric patients in lumbar MRI. Pediatr Radiol. 1995;25:186-9.

69. Benneker LM, Heini PF, Anderson SE, Alini M, Ito K. Correlation of radiographic and MRI parameters to morphological and biochemical assessment of intervertebral disc degeneration. Eur Spine J. 2005;14:27-35.

70. Griffith JF, Wang YX, Antonio GE, Choi KC, Yu A, Ahuja AT, Leung PC. Modified Pfirrmann grading system for lumbar intervertebral disc degeneration. Spine (Phila Pa 1976). 2007;32:E708-12.

71. Pfirrmann CW, Metzdorf A, Zanetti M, Hodler J, Boos N. Magnetic resonance classification of lumbar intervertebral disc degeneration. Spine (Phila Pa 1976). 2001;26:1873-8.

72. Thompson JP, Pearce RH, Schechter MT, Adams ME, Tsang IK, Bishop PB. Preliminary evaluation of a scheme for grading the gross morphology of the human intervertebral disc. Spine (Phila Pa 1976). 1990;15:411-5.

73. Vangeneugden $T$, Laenen A, Geys H, Renard D, Molenberghs G. Applying concepts of generalizability theory on clinical trial data to investigate sources of variation and their impact on reliability. Biometrics. 2005;61:295-304.

74. Liuke $M$, Solovieva $S$, Lamminen $A$, Luoma $K$, Leino-Arjas $P$, Luukkonen $R$, Riihimäki $H$. Disc degeneration of the lumbar spine in relation to overweight. Int J Obes (Lond). 2005;29:903-8.

75. Waris E, Eskelin M, Hermunen $\mathrm{H}$, Kiviluoto O, Paajanen $\mathrm{H}$. Disc degeneration in low back pain: a 17 -year follow-up study using magnetic resonance imaging. Spine (Phila Pa 1976). 2007;32:681-4. 